\title{
Carbon for nutrient exchange between Lycopodiella inundata and Mucoromycotina fine root endophytes is unresponsive to high atmospheric $\mathrm{CO}_{2}$
}

\author{
Grace A. Hoysted ${ }^{1}$ (D ) Jill Kowal ${ }^{2} \cdot$ Silvia Pressel $^{3} \cdot$ Jeffrey G. Duckett ${ }^{3} \cdot$ Martin I. Bidartondo $^{2,4} \cdot$ Katie J. Field ${ }^{1}$
}

Received: 19 February 2021 / Accepted: 14 April 2021 / Published online: 21 April 2021

(c) The Author(s) 2021

\begin{abstract}
Non-vascular plants associating with arbuscular mycorrhizal (AMF) and Mucoromycotina 'fine root endophyte' (MFRE) fungi derive greater benefits from their fungal associates under higher atmospheric $\left[\mathrm{CO}_{2}\right]\left(\mathrm{a}_{2}\left[\mathrm{CO}_{2}\right]\right)$ than ambient; however, nothing is known about how changes in $\mathrm{a}\left[\mathrm{CO}_{2}\right]$ affect MFRE function in vascular plants. We measured movement of phosphorus (P), nitrogen $(\mathrm{N})$ and carbon $(\mathrm{C})$ between the lycophyte Lycopodiella inundata and Mucoromycotina fine root endophyte fungi using ${ }^{33} \mathrm{P}$-orthophosphate, ${ }^{15} \mathrm{~N}$-ammonium chloride and ${ }^{14} \mathrm{CO}_{2}$ isotope tracers under ambient and elevated $\mathrm{a}\left[\mathrm{CO}_{2}\right]$ concentrations of 440 and $800 \mathrm{ppm}$, respectively. Transfers of ${ }^{33} \mathrm{P}$ and ${ }^{15} \mathrm{~N}$ from MFRE to plants were unaffected by changes in $\mathrm{a}\left[\mathrm{CO}_{2}\right]$. There was a slight increase in $\mathrm{C}$ transfer from plants to MFRE under elevated $\mathrm{a}\left[\mathrm{CO}_{2}\right]$. Our results demonstrate that the exchange of $\mathrm{C}$-for-nutrients between a vascular plant and Mucoromycotina FRE is largely unaffected by changes in $\left.\mathrm{a}_{[} \mathrm{CO}_{2}\right]$. Unravelling the role of MFRE in host plant nutrition and potential C-for- $\mathrm{N}$ trade changes between symbionts under different abiotic conditions is imperative to further our understanding of the past, present and future roles of plant-fungal symbioses in ecosystems.
\end{abstract}

Keywords Atmospheric $\mathrm{CO}_{2} \cdot$ Endogonales $\cdot$ Fine root endophytes $\cdot$ Lycopodiella inundata $\cdot$ Mucoromycotina $\cdot$ Vascular plants

\section{Introduction}

Changes in atmospheric $\mathrm{CO}_{2}$ concentration $\left(\mathrm{a}\left[\mathrm{CO}_{2}\right]\right)$ have been a prominent feature throughout Earth's environmental history (Leaky and Lau 2012). Geochemical models support fossil and stable isotope evidence indicating that the global environment underwent major changes throughout the Palaeozoic Era (541-250 Ma) (Berner et al. 2006; Bergman et al. 2004; Lenton et al. 2016), consisting of a stepwise

Grace A. Hoysted

g.hoysted@sheffield.ac.ukAbstract

1 Deparment of Animal and Plant Sciences, University of Sheffield, Sheffield S10 2TN, UK

2 Comparative Plant \& Fungal Biology, Royal Botanic Gardens, Kew, Richmond TW9 3DS, UK

3 Department of Life Sciences, Natural History Museum, London SW7 5BD, UK

4 Department of Life Sciences, Imperial College London, London SW7 2AZ, UK increase of the Earth's atmospheric oxygen $\left(\left[\mathrm{O}_{2}\right]\right)$, and a simultaneous decline in $\mathrm{a}\left[\mathrm{CO}_{2}\right]$. Today, Earth faces environmental changes on a similar scale, but with a $\left[\mathrm{CO}_{2}\right]$ instead rising at an unprecedented rate (Meinshausen et al. 2011; Wilson et al. 2017).

Long before plants migrated onto land, Earth's terrestrial surfaces were colonised by a diverse array of microbes, including filamentous fungi (Blair 2009; Berbee et al. 2017). Around $500 \mathrm{Mya}$, plants made the transition from an aquatic to a terrestrial existence (Morris et al. 2018), facilitated by symbiotic fungi (Nicolson 1967; Pirozynski and Malloch 1975). These ancient fungal symbionts are thought to have played an important role in helping early land plants access scarce nutrients from the substrate onto which they had emerged, in much the same way as modern-day mycorrhizal fungi form nutritional mutualisms with plants (Pirozynski and Malloch 1975; Krings et al. 2012; Strullu-Derrien et al. 2014). It is highly likely that ancient mycorrhiza-like (or paramycorrhiza sensu Strullu-Derrien and Strullu 2007) fungi were closely related to, and subsequently evolved into, modern arbuscular mycorrhizal fungi (AMF) belonging to 
the fungal subphylum Glomeromycotina (also referred to as phylum Glomeromycota) (Redecker et al. 2000; Spatafora et al. 2017; Wijayawardene et al. 2018; Radhakrishnan et al. 2020).

Recently, it was discovered that extant non-vascular plants, including the earliest divergent clade of liverworts, associate with a greater diversity of fungi than was previously thought, notably forming endophytic associations with Endogonales, members of the Mucoromycotina (Bidartondo et al. 2011; Desirò et al. 2014; Strullu-Derrien et al. 2014; Rimington et al. 2015; Field et al. 2015a). Mucoromycotina is a partially saprotrophic fungal lineage (Bidartondo et al. 2011; Field et al. 2015b, 2016) sister to, or pre-dating, the Glomeromycotina AMF, both within Mucoromycota (Spatafora et al. 2017). This discovery, together with the emerging fossil evidence (Strullu-Derrien et al. 2014) and the demonstration that liverwort-Mucoromycotina fungal associations are nutritionally mutualistic (Field et al. 2015a; 2019) and often co-occur with AMF (Field et al. 2016), suggests that earlier land plants had greater symbiotic options available to them than was previously thought (Field et al. 2015b). Studies now show that symbioses with Mucoromycotina fungi are not limited to non-vascular plants but span almost the entire extant land plant kingdom (Rimington et al. 2015, 2020; Orchard et al. 2017a; Hoysted et al. 2018, 2019), suggesting that this ancient association may also have key roles in modern terrestrial ecosystems.

The latest research into the functional significance of plant-Mucoromycotina fine root endophyte (MFRE) associations indicates that MFRE play a complementary role to AMF by facilitating plant nitrogen $(\mathrm{N})$ assimilation alongside AMF-facilitated plant phosphorus (P) acquisition through co-colonisation of the same plant host (Field et al. 2019). Such functional complementarity is further supported by the observation that MFRE transfer significant amounts of ${ }^{15} \mathrm{~N}$ but relatively little ${ }^{33} \mathrm{P}$ tracers to a host lycophyte, Lycopodiella inundata, in the first experimental demonstration of MFRE nutritional mutualism in a vascular plant (Hoysted et al. 2019). These results contrast with the majority of studies on MFRE and fine root endophytes (FRE) which have, to date, focussed on the role of the fungi in mediating plant phosphorus (P) acquisition (Orchard et al. 2017b, and literature within; Albornoz et al. 2020).

Today, plant-symbiotic fungi play critical roles in ecosystem structure and function. The bidirectional exchange of plant-fixed carbon (C) for fungal-acquired nutrients that is characteristic of most mycorrhizal symbioses (Field and Pressel 2018) holds huge significance for carbon and nutrient flows and storage across ecosystems (Leake et al. 2004; Rillig 2004; Averill et al. 2014). By forming mutualistic symbioses with the vast majority of plants, including economically important crops, mycorrhizal fungi have great potential for applications within a variety of sustainable management strategies in agriculture, conservation and restoration. Application of diverse mycorrhiza-forming fungi, including both AMF and MFRE, to promote sustainability in agricultural systems is particularly relevant in the context of global climate change and depletion of natural resources (Field et al. 2020). The MFRE in particular may hold potential for agricultural applications to reduce use of chemical fertilisers within sustainable arable systems where routine over-use of $\mathrm{N}$-based mineral fertilisers causes detrimental environmental and down-stream economic impacts (Thirkell et al. 2019), but realising this potential relies on improving our current understanding of MFRE diversity and function. Changes in abiotic factors such as a $\left[\mathrm{CO}_{2}\right]$ (Cotton 2018), which is predicted to continue rising in the future (Meinshausen et al. 2011), have been shown to affect the rate and quantity of carbon and nutrients exchanged between mycorrhizal partners (Field et al. 2012, 2015a, 2016; Zheng et al. 2015; Thirkell et al. 2019). As such, insights into the impact of environmental factors relevant to future climate change on carbon for nutrient exchange between symbiotic fungi and plants must be a critical future research goal.

Experiments with liverworts associating with MFRE fungi, either in exclusive or in dual symbioses alongside AMF, suggest that these plants derive less benefit in terms of nutrient assimilation from their MFRE associates under a high a $\left[\mathrm{CO}_{2}\right](1500 \mathrm{ppm})$ than under a lower a $\left[\mathrm{CO}_{2}\right]$ (440 ppm) (Field et al. 2015a, 2016), with the opposite being the case for liverworts associated only with AMF (Field et al. 2012). However, when vascular plants (Osmunda regalis and Plantago lanceolata) with AMF associations were exposed to high a[ $\left.\mathrm{CO}_{2}\right]$, there were no changes in mycorrhizal-acquired plant $\mathrm{P}$ assimilation (Field et al. 2012). Whether vascular plant-MFRE symbioses respond to changing $\mathrm{a}\left[\mathrm{CO}_{2}\right]$ is unknown.

Here, using stable and radioisotope tracers, we investigate MFRE function in Lycopodiella inundata, a homosporous perennial lycophyte widely distributed in the northern hemisphere (Rasmussen and Lawesson 2002) that associates almost exclusively with MFRE fungal partners (Kowal et al. 2020), and how it responds to climate change-relevant shifts in $\mathrm{a}\left[\mathrm{CO}_{2}\right]$. Specifically, we test the hypotheses that (a) MFRE acquire greater amounts of plant-fixed $\mathrm{C}$ under high $\mathrm{a}\left[\mathrm{CO}_{2}\right]$ of $800 \mathrm{ppm}$ as a result of there being larger amounts of photosynthate available for transfer because of greater rates of $\mathrm{C}$ fixation by the plant via photosynthesis, and (b), increased $\mathrm{C}$ allocation from plant to fungus increases transfer and assimilation of ${ }^{15} \mathrm{~N}$ and ${ }^{33} \mathrm{P}$ tracers from MFRE to plants to feed growing plant demand for nutrients to promote growth. 


\section{Methods}

\section{Plant material and growth conditions}

Mature Lycopodiella inundata (L.) plants were collected from the wild in Thursley National Nature Reserve, Surrey, UK (SU 90,081 39,754), in June 2017. The L. inundata plants, which were weeded regularly to remove other plant species, were planted directly into pots (90$\mathrm{mm}$ diameter $\times 85-\mathrm{mm}$ depth) containing a homogeneous mixture of acid-washed silica sand and $5 \%$ pot volume compost (No. 2; Petersfield) to aid retention properties of the substrate and to provide minimal nutrients. Soil surrounding plant roots (approximately one-fifth of the pot volume) was left intact to prevent damage to the roots and to act as a natural inoculum, including symbiotic fungi and associated microorganisms.

Based on the methods of Field et al. (2012), three windowed cylindrical plastic cores covered in $10-\mu \mathrm{m}$ nylon mesh were inserted into the substrate within each experimental pot (see supplementary online material Fig. S1). Two of the cores were filled with the same substrate as the bulk soil within the pots, comprising a homogeneous mixture of acid-washed silica sand and compost (No. 2; Petersfield), together making up 95\% of the core volume, native soil gathered from around the roots of wild plants to ensure cores contained the same microbial communities as in the bulk soil ( $4 \%$ core volume), and fine-ground tertiary basalt (1\% core volume) to act as fungal bait (Field et al. 2015a). The third core was filled with glass wool to allow below-ground gas sampling throughout the ${ }^{14} \mathrm{C}$-labelling period to monitor soil community respiration. Plants were watered every other day with distilled water with no other application of nutrient solutions. Microcosms shared a common drip tray within each cabinet only through the acclimation period, ensuring a common pool of rhizospheric microorganisms in each microcosm.

A total of $48 \mathrm{~L}$. inundata microcosms were maintained in controlled environment chambers (model no. Micro Clima 1200; Snijders Labs) with a light cycle of 16-h daytime $\left(20{ }^{\circ} \mathrm{C}\right.$ and $70 \%$ humidity) and 8 -h night-time (at $15{ }^{\circ} \mathrm{C}$ and $70 \%$ humidity). Daytime photosynthetically active radiation (PAR), supplied by LED lighting, was $225 \mu \mathrm{mol}$ photons $\mathrm{m}^{-2} \mathrm{~s}^{-1}$ (similar to what $L$. inundata experience in the wild). Plants were grown at two contrasting $\mathrm{CO}_{2}$ atmospheres: $440 \mathrm{ppm}$ a[ $\left.\mathrm{CO}_{2}\right]$ (24 plants) to represent a modern-day atmosphere or $800 \mathrm{ppm} \mathrm{a}\left[\mathrm{CO}_{2}\right]$ (24 plants) to simulate Palaeozoic atmospheric conditions on Earth at the time vascular plants are thought to have diverged (Berner 2006) as well as predicted $\mathrm{a}\left[\mathrm{CO}_{2}\right]$ for 2100 (Meinshausen et al. 2011). Atmospheric $\left[\mathrm{CO}_{2}\right]$ was monitored using a Vaisala sensor system (Vaisala,
Birmingham, UK), maintained through addition of gaseous $\mathrm{CO}_{2}$. All pots were rotated within cabinets, and plants were switched between cabinets with $\mathrm{a}\left[\mathrm{CO}_{2}\right]$ adjusted accordingly every 2 weeks to control for possible cabinet and block effects. Plants were acclimated to chamber/growth regimes for 4 weeks to allow establishment of mycelial networks within pots. Before initiation of radioisotope labelling, mycelial networks were confirmed by destructively collecting soil from a rotated core for hyphal extraction and subsequent staining with trypan blue (Brundrett et al. 1996). Additionally, main roots were stained with acidified ink for the presence of fungi, based on the methods of Brundrett et al. (1996). All plants were processed for molecular identification of fungal symbionts within 1 week of collection from the wild and at the end of the experimental period using the protocol in Hoysted et al. (2019). Briefly, genomic DNA extraction and purification from $L$. inundata roots and subsequent amplification, cloning and sequencing were performed according to the methods of Rimington et al. (2015). The fungal 18S ribosomal rRNA gene was targeted using the fungal primer set NS1/ EF3 and a semi-nested approach with Mucoromycotinaand Glomeromycotina-specific primers described in Desirò et al. (2014).

\section{Cytological analyses}

Roots of experimental L. inundata plants were stained with trypan blue (Brundrett et al. 1996), which is common for identifying MFRE (Orchard et al. 2017b), and photographed under a Zeiss Axioscope (Zeiss, Oberkochen, Germany) equipped with a MRc digital camera. To quantify root colonisation by MFRE, five plants were randomly selected per treatment, and from these two intact, healthy roots (per plant) were excised and sectioned transversally in up to six segments (depending on root length) before being processed for scanning electron microscopy according to Duckett et al. (2006). Percentage root colonisation was then calculated by scoring each segment (from a total of 56 and 58 segments respectively for the elevated and ambient $\mathrm{a}\left[\mathrm{CO}_{2}\right]$ treatments) as colonised or noncolonised under the scanning electron microscope (Fig. 1).

Quantification of $\mathrm{C},{ }^{33} \mathrm{P}$ and ${ }^{15} \mathrm{~N}$ fluxes between lycophytes and fungi.

After the 4-week acclimation period, microcosms were moved to individual drip trays immediately before isotope labelling to avoid cross-contamination of the isotope tracers. A total of $100 \mu 1$ of an aqueous mixture of ${ }^{33} \mathrm{P}$-labelled orthophosphate (specific activity $111 \mathrm{TBq} \mathrm{mmol}^{-1}, 0.3 \mathrm{ng}$ ${ }^{33} \mathrm{P}$ added; Hartmann analytics) and ${ }^{15} \mathrm{~N}$-ammonium chloride $\left(1 \mathrm{mg} \mathrm{ml}^{-1} ; 0.1 \mathrm{mg}{ }^{15} \mathrm{~N}\right.$ added; Sigma-Aldrich) was introduced into one of the soil-filled mesh cores in each pot through the installed capillary tube. In half $(n=12)$ of 


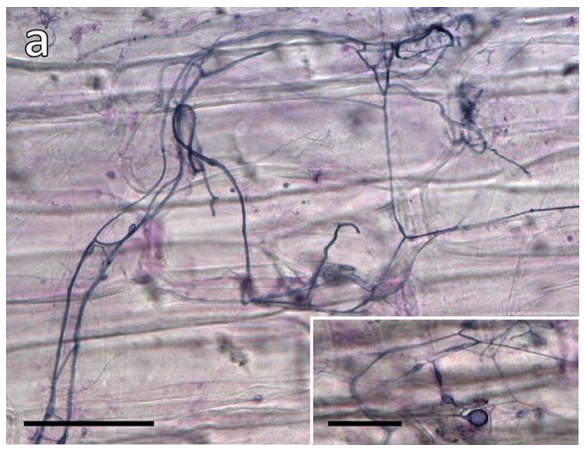

Fig. 1 Experimental Lycopodiella roots colonised by MFRE. a Light micrographs of trypan blue stained roots showing fine branching hyphae with intercalary and terminal small vesicles (see insert). b Scanning electron micrograph (SEM) of transverse section of root showing abundant branching hyphae $(*)$ and vesicles (arrowed).

the pots, cores containing isotope tracers were left static to preserve direct hyphal connections with the lycophytes. Fungal access to isotope tracers was limited in the remaining half (12) of the pots by rotating isotope tracer-containing cores through $90^{\circ}$, thereby severing the hyphal connections between the plants and core soil. These were rotated every second day thereafter, thus providing a control treatment that allows us to distinguish between fungal and microbial contributions to tracer uptake by plants, as well as passive diffusion of isotopes through the soil matrix. Assimilation of ${ }^{33} \mathrm{P}$ tracer into above-ground plant material was monitored using a hand-held Geiger counter held over the plant material daily.

At detection of peak activity in above-ground plant tissues (21 days after the addition of the ${ }^{33} \mathrm{P}$ and ${ }^{15} \mathrm{~N}$ tracers), the tops of ${ }^{33} \mathrm{P}$ and ${ }^{15} \mathrm{~N}$-labelled cores were sealed with plastic caps and anhydrous lanolin, and the glass-wool cores were sealed with rubber septa (Suba-Seal, Sigma-Aldrich). Before lights were switched on at 8 a.m., each pot was sealed into a 3.5-l, gas-tight labelling chamber, and $2 \mathrm{ml} 10 \%(\mathrm{w} / \mathrm{v})$ lactic acid was added to $30 \mu \mathrm{l} \mathrm{NaH}{ }^{14} \mathrm{CO}_{3}$ (specific activity $1.621 \mathrm{GBq} / \mathrm{mmol}^{-1}$; Hartmann Analytics), releasing a 1.1MBq pulse of ${ }^{14} \mathrm{CO}_{2}$ gas into the headspace of the labelling chamber. Pots were maintained under growth chamber conditions, and $1 \mathrm{ml}$ of headspace gas was sampled after $1 \mathrm{~h}$ and every $1.5 \mathrm{~h}$ thereafter. Below-ground respiration was monitored via gas sampling from within the glass-wool-filled core after $1 \mathrm{~h}$ and every $1.5 \mathrm{~h}$ thereafter for $\sim 16 \mathrm{~h}$.

\section{Plant harvest and sample analyses}

Upon detection of maximum below-ground flux of ${ }^{14} \mathrm{C}, \sim 16 \mathrm{~h}$ after the release of the ${ }^{14} \mathrm{CO}_{2}$ pulse, each microcosm compartment (i.e. plant material and soil) was separated, freeze-dried, weighed and homogenised using a

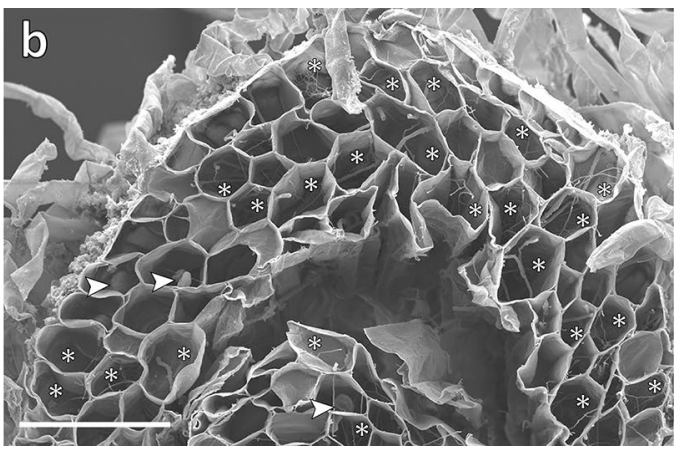

SEMs at this magnification $(\times 150)$ were used to quantify $\%$ colonisation of roots of experimental plants grown under the two contrasting atmospheric $\left[\mathrm{CO}_{2}\right]$ regimes, shown here in a plant grown under the elevated $\mathrm{a}\left[\mathrm{CO}_{2}\right]$ of $800 \mathrm{ppm}$. Scale bars: a (and a insert) $50 \mu \mathrm{m} ; \mathbf{b}$ $100 \mu \mathrm{m}$

TissueLyser LT with steel ball bearings (Qiagen). The ${ }^{33} \mathrm{P}$ activity in plant (shoots and roots) and soil samples (cores and bulk) was quantified by digesting in concentrated $\mathrm{H}_{2} \mathrm{SO}_{4}$ and liquid scintillation (Tricarb 3100TR liquid scintillation analyser, Isotech). The quantity of ${ }^{33} \mathrm{P}$ tracer that was transferred to a plant by its fungal partner was then calculated using previously published equations (Cameron et al. 2007). To determine total symbiotic fungal-acquired ${ }^{33} \mathrm{P}$ transferred to $L$. inundata, the mean ${ }^{33} \mathrm{P}$ content of plants that did not have access to the tracer because cores into which the ${ }^{33} \mathrm{P}$ was introduced were rotated was subtracted from the total ${ }^{33} \mathrm{P}$ in each plant that did have access to the isotopes within the core via intact fungal hyphal connections (i.e. static cores). This calculation controls for diffusion of isotopes and microbial nutrient cycling in pots, ensuring only ${ }^{33} \mathrm{P}$ gained by the plant via intact fungal hyphal connections, are accounted and therefore serve as a conservative measure of the minimum fungal transfer of tracer to the plant.

Between 2 and $4 \mathrm{mg}$ of freeze-dried, homogenised plant tissue (both shoots and roots, separately) was weighed into $6 \times 4 \mathrm{~mm}^{2}$ tin capsules (Sercon), and ${ }^{15} \mathrm{~N}$ abundance was determined using a continuous flow IRMS (PDZ 2020 IRMS, Sercon). Air was used as the reference standard, and the IRMS detector was regularly calibrated to commercially available reference gases. The ${ }^{15} \mathrm{~N}$ transferred from fungus to plant was then calculated using equations published previously in Field et al. (2016). In a similar manner as for the ${ }^{33} \mathrm{P}$, the mean of the total ${ }^{15} \mathrm{~N}$ in plants without access to the isotope because of broken hyphal connections between plant and core contents was subtracted from total ${ }^{15} \mathrm{~N}$ in each plant with intact hyphal connections to the mesh-covered core to give fungal-acquired ${ }^{15} \mathrm{~N}$. Again, this provides a conservative measure of ${ }^{15} \mathrm{~N}$ transfer from fungus to plant as it ensures only ${ }^{15} \mathrm{~N}$ gained by the plant via intact fungal hyphal connections is accounted. 
The ${ }^{14} \mathrm{C}$ activity of plant (shoots and roots) and soil (cores and bulk) samples was quantified through sample oxidation (307 Packard Sample Oxidiser, Isotech) followed by liquid scintillation. Total $\mathrm{C}\left({ }^{12} \mathrm{C}+{ }^{14} \mathrm{C}\right)$ fixed by the plant and transferred to the fungal network was calculated as a function of the total volume and $\mathrm{CO}_{2}$ content of the labelling chamber and the proportion of the supplied ${ }^{14} \mathrm{CO}_{2}$ label fixed by plants. The difference in total $\mathrm{C}$ between the values obtained for static and rotated core contents in each pot is considered equivalent to the total $\mathrm{C}$ transferred from plant to symbiotic fungus within the soil core for that microcosm, noting that a small proportion will be lost through soil microbial respiration (Cameron et al. 2006). The total $\mathrm{C}$ budget for each experimental pot was calculated using equations from Cameron et al. (2006). Total percent allocation of plant-fixed $\mathrm{C}$ to extraradical symbiotic fungal hyphae was calculated by subtracting the activity (in becquerels, $\mathrm{Bq}$ ) of rotated core samples from that detected in static core samples in each pot, dividing this by the sum of activity detected in all components (shoots, roots, static and rotated cores, and bulk soil) of each microcosm, then multiplying it by 100 .

\section{Statistics}

Effects of $\mathrm{a}\left[\mathrm{CO}_{2}\right]$ on the $\mathrm{C},{ }^{33} \mathrm{P}$ and ${ }^{15} \mathrm{~N}$ fluxes between $L$. inundata and MFRE fungi were tested using analysis of variance (ANOVA) or Mann-Whitney $U$ where indicated. Data were checked for homogeneity and normality using the Kolmogorov-Smirnov test. Where assumptions for ANOVA were not met, data were transformed using $\log _{10}$. If assumptions for ANOVA were still not met, a Mann-Whitney $U$ test was performed. Significant differences comparing the proportion of root segments colonised and differences across the population of root segments were analysed using a Fisher's exact and an unpaired $t$-test, respectively. All statistics were carried out using the statistical software package SPSS Version 24 (IBM Analytics).

\section{Results}

\section{Molecular identification of fungal symbionts}

Analysis of experimental Lycopodiella inundata plants grown under ambient and elevated $\mathrm{a}\left[\mathrm{CO}_{2}\right]$ confirmed that they were colonised by Mucoromycotina fine root endophyte fungi within Endogonales. Glomeromycotina fungal sequences were not detected. Mucoromycotina OTUs that have previously been identified in wild-collected lycophytes from diverse locations (Rimington et al. 2015; Hoysted et al. 2019) were detected before and after the experiments (GenBank/EMBL accession numbers: MK673773-MK673803).

\section{Cytology of fungal colonisation in plants}

Trypan blue staining and SEM of L. inundata roots grown under ambient and elevated $\mathrm{a}\left[\mathrm{CO}_{2}\right]$ revealed the same fungal symbiont morphology consistent with that previously observed for L. inundata-Mucoromycotina FRE (Hoysted et al. 2019) and MFRE colonisation in other vascular plants (Orchard et al. 2017a) including fine branching, aseptate hyphae $(<2-\mu \mathrm{m}$ diameter) with small intercalary and terminal swellings/vesicles (usually 5-10- but up to $15-\mu \mathrm{m}$ diameter) but, differently from those in flowering plants, no arbuscules (Fig. 1). There was a significant difference across the population of root segments in the percentage of individual root fragments colonised grown under contrasting $\mathrm{a}\left[\mathrm{CO}_{2}\right]$ (supplementary online material Fig. S2). Root segments from plants grown under 440 $\mathrm{a}\left[\mathrm{CO}_{2}\right]$ had a significantly lower mean percent colonisation compared to root segments from plants grown under $800 \mathrm{ppm} \mathrm{a}\left[\mathrm{CO}_{2}\right](t=2.182 ; d f=106.9, n=58,54)$.

\section{C transfer from $L$. inundata to MFRE symbionts}

The amount of carbon allocated from L. inundata to MFRE fungi under elevated $\mathrm{a}\left[\mathrm{CO}_{2}\right]$ concentrations compared to that when plants were grown under $\mathrm{a}\left[\mathrm{CO}_{2}\right]$ of $440 \mathrm{ppm}$ was not statistically significant (Fig. 2a; Mann-Whitney $U=194, P=0.864, n=24$ ); nevertheless, the transfer was 2.8 times greater at $800 \mathrm{ppm}$ than at $440 \mathrm{ppm}$. In terms of total C transferred from plants to MFRE (carbon in core, ng), similarly, $L$. inundata transferred ca. 2.7 times more C to MFRE fungal partners at elevated $\mathrm{a}\left[\mathrm{CO}_{2}\right]$ concentrations of $800 \mathrm{ppm}$ compared to those under a $\left[\mathrm{CO}_{2}\right]$ of $440 \mathrm{ppm}$ (Fig. 2b; Mann-Whitney $U=197.5, P=0.942, n=24$ ).

\section{Fungus-to-lycophyte ${ }^{33} \mathrm{P}$ and ${ }^{15} \mathrm{~N}$ transfer}

Mucoromycotina FRE transferred both ${ }^{33} \mathrm{P}$ and ${ }^{15} \mathrm{~N}$ to $L$. inundata in both $\mathrm{a}\left[\mathrm{CO}_{2}\right]$ treatments (Fig. 3). There were no significant differences in the amounts of either ${ }^{33} \mathrm{P}$ or ${ }^{15} \mathrm{~N}$ tracer acquired by MFRE in $L$. inundata plant tissue when grown under elevated $\mathrm{a}\left[\mathrm{CO}_{2}\right]$ of $800 \mathrm{ppm}$ compared to plants grown under a $\left[\mathrm{CO}_{2}\right]$ conditions of $440 \mathrm{ppm}$, either in terms of absolute quantities (Fig. 3a; ANOVA $\left[F_{1,23}=0.009, P=0.924, n=10\right]$; Fig. $3 b$; ANOVA $\left[F_{1,22}=0.126, P=0.726, n=10\right]$ ) or when normalised to plant biomass (Fig. 3c ANOVA $\left[F_{1,23}=0.085\right.$, $P=0.774, n=10]$; Fig. 3d; ANOVA $\left[F_{1,22}=0.770, P=0.390\right.$, $n=10])$. Although not significantly different, there was more nitrogen transferred from MFRE under ambient a $\left[\mathrm{CO}_{2}\right] \mathrm{com}$ pared to elevated $\mathrm{a}\left[\mathrm{CO}_{2}\right]$ (Fig. 3d). Within the experimental microcosms, MFRE transferred $6.65 \%( \pm 2.55){ }^{33} \mathrm{P}$ and $0.07 \%$ $( \pm 0.02){ }^{15} \mathrm{~N}$ tracer under ambient $\mathrm{a}\left[\mathrm{CO}_{2}\right]$ and $6.9 \%( \pm 4.75)$

${ }^{33} \mathrm{P}$ and $0.03 \%( \pm 0.18){ }^{15} \mathrm{~N}$ tracer under elevated $\mathrm{a}\left[\mathrm{CO}_{2}\right]$. 


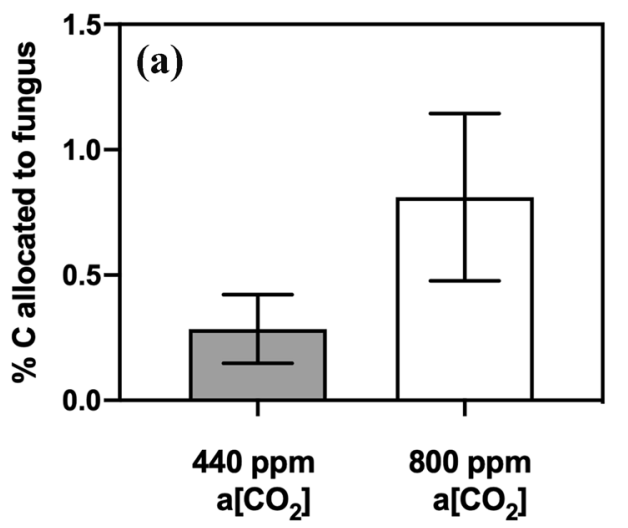

Fig. 2 Carbon exchange between Lycopdiella inundata and Mucoromycotina fine root endophyte fungi (MFRE). (a) \% allocation of plant-fixed C to MFRE. (b) Total plant-fixed C transferred to Mucorocomycotina FRE by L. inundata. All experiments were conducted at an ambient $\mathrm{a}\left[\mathrm{CO}_{2}\right]$ of $440 \mathrm{ppm}$ (grey bars) and elevated $\mathrm{a}\left[\mathrm{CO}_{2}\right]$

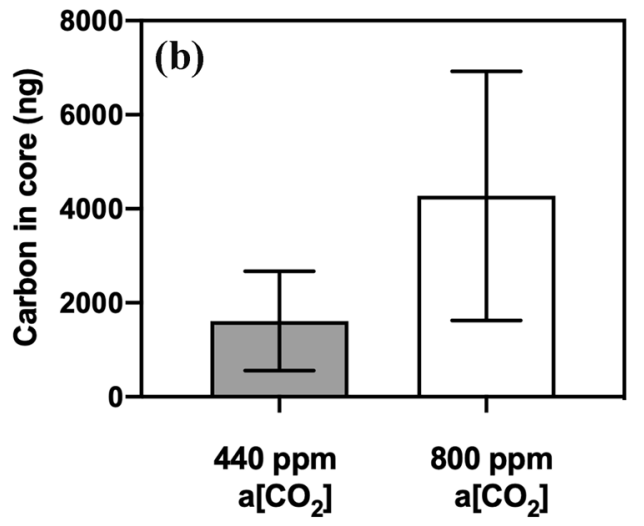

of 800 ppm (white bars). All bars in each panel represent the difference in isotopes between the static and rotated cores inserted into each microcosm. In all panels, error bars denote standard error of the mean. In panels (a, b), $n=24$ for $800 \mathrm{ppm}$ and for $440 \mathrm{ppm} \mathrm{a}\left[\mathrm{CO}_{2}\right]$
Fig. 3 Fungal-acquired nutrients by Mucoromycotina fine root endophyte (MFRE) fungi and total shoot nutrients in above-ground plant tissue of $L$. inundata. (a) Total plant tissue ${ }^{33} \mathrm{P}$ content (ng) and (b) total plant tissue ${ }^{15} \mathrm{~N}$ content (ng) in L. inundata tissue. (c) Tissue concentration $\left(\mathrm{ng} \mathrm{g}^{-1}\right)$ of fungal-acquired ${ }^{33} \mathrm{P}$ and (d) tissue concentration of ${ }^{15} \mathrm{~N}$ $\left(\mathrm{ng} \mathrm{g}^{-1}\right)$ in shoot tissue of $L$. inundata. (e) Total shoot $\mathrm{P}$ content (mg) equating to both plant and fungal-acquired $\mathrm{P}$ and (f) total shoot $\mathrm{N}$ content $(\mathrm{mg})$ equating to both plant and fungal-acquired $\mathrm{N}$ in shoots of L. inundata. All experiments were conducted at an ambient $\mathrm{a}\left[\mathrm{CO}_{2}\right]$ of $440 \mathrm{ppm}$ (grey bars) and elevated $\mathrm{a}\left[\mathrm{CO}_{2}\right]$ of $800 \mathrm{ppm}$ (white bars). All bars in each panel (a-d) represent the difference in isotopes between the static and rotated cores inserted into each microcosm. In all panels, error bars denote standard error of the mean. In panels (a-d), $n=12$, and panels (e-f), $n=24$, for both $800 \mathrm{ppm}$ and $440 \mathrm{ppm}$ a $\left[\mathrm{CO}_{2}\right]$
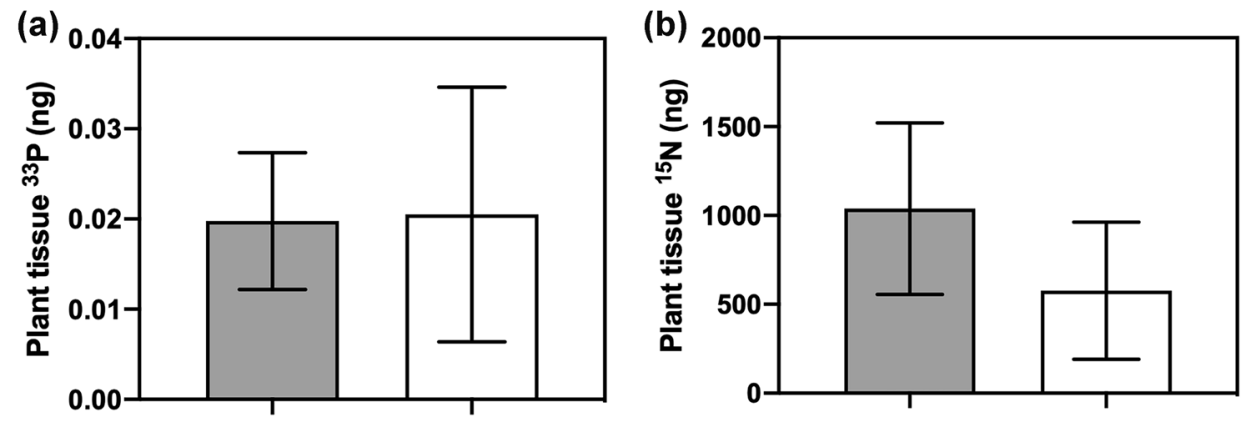

(c)

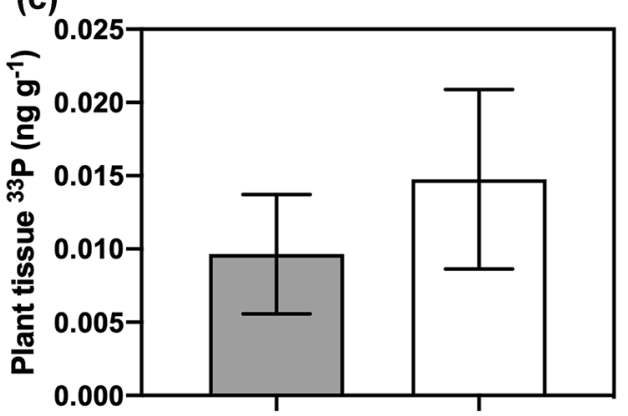

(d)
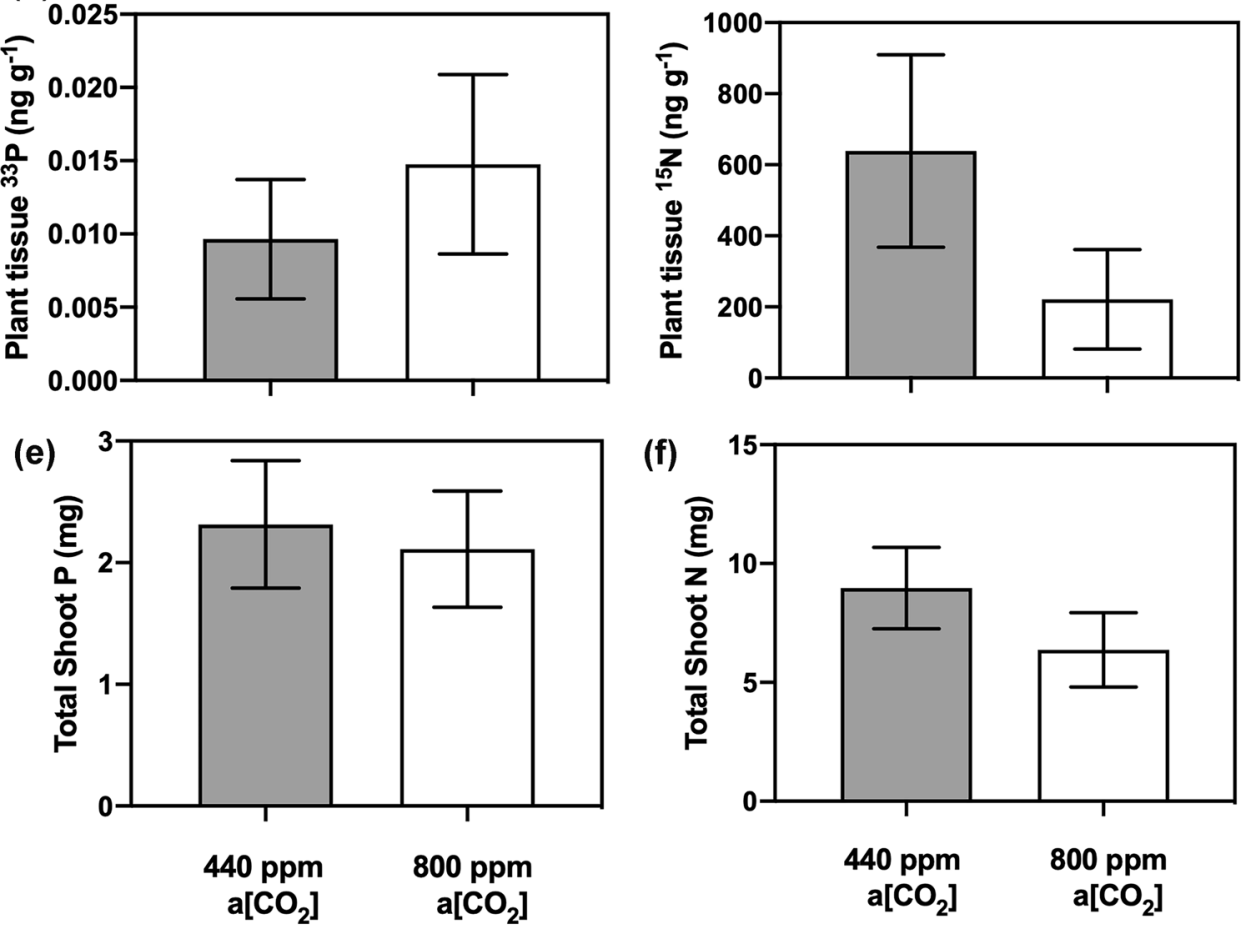

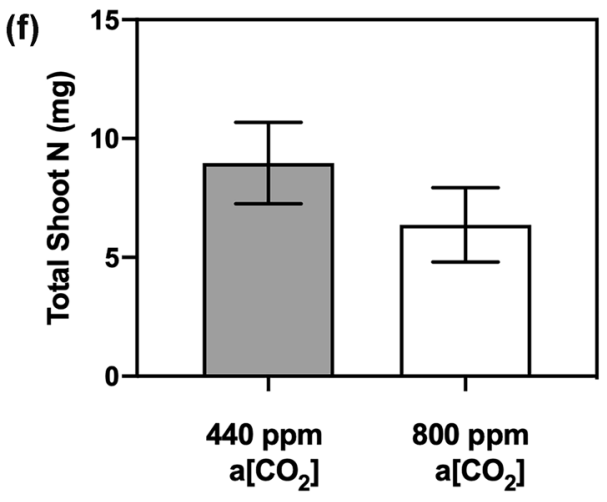




\section{Discussion}

Our results demonstrate for the first time that the exchange of C-for-nutrients between a vascular plant and MFRE symbionts is largely unaffected by changes in $\mathrm{a}\left[\mathrm{CO}_{2}\right]$, with MFRE maintaining ${ }^{33} \mathrm{P}$ and ${ }^{15} \mathrm{~N}$ assimilation and transfer to the plant host across a $\left[\mathrm{CO}_{2}\right]$ treatments (Fig. 3a, b), despite MFRE colonisation being more abundant within the roots of plants grown under elevated $\mathrm{a}\left[\mathrm{CO}_{2}\right]$. In our experiments, Lycopodiella inundata allocated ca. 2.8 times more photosynthate to MFRE under elevated $\mathrm{a}\left[\mathrm{CO}_{2}\right]$ compared with plants that were grown under ambient $\mathrm{a}\left[\mathrm{CO}_{2}\right]$ (Fig. 2a, b), but without a reciprocal increase in fungal-acquired ${ }^{33} \mathrm{P}$ or ${ }^{15} \mathrm{~N}$ tracer assimilation. Although the difference in $\mathrm{C}$ transfer between plants under different $\mathrm{a}\left[\mathrm{CO}_{2}\right]$ atmospheres was not statistically significant, our observation is in line with previous studies in which Mucoromycotina fungi (and both Mucoromycotina and AMF partners co-colonising the same host in 'dual' symbiosis) gained a greater proportion of recently fixed photosynthates from their non-vascular plant partners but did not deliver greater amounts of ${ }^{33} \mathrm{P}$ or ${ }^{15} \mathrm{~N}$ tracers when grown under elevated $\mathrm{a}\left[\mathrm{CO}_{2}\right]$ compared to current ambient conditions (Field et al. 2012, 2015a, 2016). This contrasts with patterns of carbon-for-nutrient exchange between other vascular plants and AMF where increased allocation of carbon to fungal symbionts is usually associated with increases in nutrient delivery from AMF to the host plant (Kiers et al. 2011; Wipf et al. 2019). Such variances may be partly explained by the different lifestyles of the partially saprotrophic Mucoromycotina vs. the strictly biotrophic Glomeromycotina (Field et al. 2015b, 2016; Field and Pressel 2018). Therefore, conventional 'rules' governing AMF-plant symbioses may not necessarily apply to Mucoromycotina-plant symbioses. It is possible that when $\mathrm{a}\left[\mathrm{CO}_{2}\right]$ is high, liverworts and relatively simple vascular plants such as L. inundata produce photosynthates that they are unable to utilise effectively for growth or reproduction as they possess no or limited vasculature and specialised storage organs to transport and store excess carbohydrates (Kenrick and Crane 1997). Consequently, surplus photosynthates may be either stored as insoluble starch granules, transferred directly to mycobionts (Field et al. 2016), or released into surrounding soil as exudates (Galloway et al. 2018). By moving excess photosynthates into mycobionts, the potential risk of pathogenicity from surrounding saprotrophic organisms such as bacteria and fungi may be reduced (Field et al. 2016).

Additionally, the biomass of mycorrhizal fungi may increase in response to elevated $\mathrm{a}\left[\mathrm{CO}_{2}\right]$, but this increase does not necessarily result in greater nutrient transfer to the host plant (Alberton et al. 2005), instead inducing a negative feedback through enhanced competition for nutrients between the symbiotic partners (Fransson et al. 2007).
Studies on ectomycorrhizal fungi, another group of widespread plant-symbiotic fungi, some of which may act as facultative decomposers, showed that, despite an increase in the amount of extraradical hyphae under elevated $\mathrm{a}\left[\mathrm{CO}_{2}\right]$, there was no corresponding enhanced transfer of $\mathrm{N}$ to the host, suggesting that the fungus had become a larger sink of nutrients (Fransson et al. 2005). While we did not measure fungal biomass in this study, our observation of greater colonisation in the roots of Lycopodiella plants grown under elevated $\mathrm{a}\left[\mathrm{CO}_{2}\right]$ of $800 \mathrm{ppm}$ compared to those grown under ambient concentrations but with no corresponding increase in fungus-to-plant $\mathrm{N}$ and $\mathrm{P}$ transfer may suggest a similar scenario.

We observed no difference in the amount of fungalacquired ${ }^{33} \mathrm{P}$ tracer transferred to $L$. inundata sporophytes between $\mathrm{a}\left[\mathrm{CO}_{2}\right]$ treatments. This aligns with the responses of MFRE symbionts in non-vascular liverworts which also transferred the same amount (or more in the case of Treubia) of ${ }^{33} \mathrm{P}$ and more ${ }^{15} \mathrm{~N}$ to plant hosts under ambient a $\left[\mathrm{CO}_{2}\right]$ compared to elevated a $\left[\mathrm{CO}_{2}\right]$ (Field et al. 2015a, 2016). The amount of ${ }^{33} \mathrm{P}$ transferred to $L$. inundata was up to 70 times less than has previously being recorded for Mucoromycotina in liverworts (Field et al. 2016) and for Glomeromycotinaassociated ferns and angiosperms (Field et al. 2012), despite the same amount of ${ }^{33} \mathrm{P}$ being made available, indicating that MFRE do not play a critical role in lycophyte P nutrition. MFRE transferred considerable amounts of ${ }^{15} \mathrm{~N}$ to their host (see also Hoysted et al. 2019), under both a $\left[\mathrm{CO}_{2}\right]$ treatments. This observation together with previous findings that MFRE facilitate the transfer of both organic and inorganic ${ }^{15} \mathrm{~N}$ to non-vascular plants (liverworts) suggest that MFRE may play a complementary role to AMF in plant nutrition, with a more prominent role in $\mathrm{N}$ assimilation than that of AMF (Field et al. 2019; Hoysted et al. 2019). While it has been shown that AMF can transfer $\mathrm{N}$ to their associated host (Ames et al. 1983; Hodge et al. 2001), significant doubts remain as to the ecological relevance of an AMF-N uptake pathway (see Read 1991; Smith and Smith 2011). In particular, the exact mechanism of $\mathrm{N}$ transfer and, more importantly, the amounts of $\mathrm{N}$ transferred via AMF compared to the $\mathrm{N}$ requirements of the plant remain equivocal (Smith and Smith 2011). This murky view of AMF in $\mathrm{N}$ transfer, coupled with recent molecular re-identification of fine root endophytes as belonging within Mucoromycotina and not Glomeromycotina (Orchard et al. 2017a) and evidence pointing to a significant role of MFRE in ${ }^{15} \mathrm{~N}$ transfer to both non-vascular (Field et al. 2015a, 2016, 2019) and vascular plants (Hoysted et al. 2019), suggests that effects on plant $\mathrm{N}$ nutrition previously ascribed to AMF instead might be attributable to co-occurring MFRE (Field et al. 2019).

Given that symbioses involving MFRE are much more widespread than initially thought, covering a wide variety 
of habitats (Bidartondo et al. 2011; Rimington et al. 2015, 2020; Orchard et al. 2017a, b, c; Hoysted et al. 2018, 2019), their role in plant $\mathrm{N}$ nutrition and responses to high a $\left[\mathrm{CO}_{2}\right]$ may have much broader ecological significance than previously assumed. It remains critical that we test how mycorrhizal plasticity (both AMF and MFRE) translates into function in order to understand how climate change may affect nutrient fluxes between symbionts in the past, present and, importantly, the future (Field and Pressel 2018).

In this study, we provide a first assessment of the effects of varying $\mathrm{a}\left[\mathrm{CO}_{2}\right]$ on carbon-for-nutrient exchanges between MFRE and a vascular plant. Our results point to important differences in responses to changing a $\left[\mathrm{CO}_{2}\right]$ between MFRE and AMF and between MFRE symbioses in vascular vs. non-vascular plants; however, these results are so far restricted to one, early diverging, vascular species, generally growing in severely $\mathrm{N}$-limited habitats. It is now critical that similar investigations are extended to a broader range of taxa, including flowering plants known to engage in symbiosis with both MFRE and AMF. In doing so, efforts towards the potential exploitation of these symbiotic fungi to help meet sustainability targets of the future may be better informed and the likelihood of success vastly improved.

Supplementary Information The online version contains supplementary material available at https://doi.org/10.1007/s00572-021-01033-6.

Acknowledgements We thank Natural England for granting permission to collect Lycopodiella from Thursley.

Author contributions KJF, SP, JGD and MIB conceived and designed the investigation. GAH undertook the physiological analyses and analysed and interpreted the results. JK undertook staining and scoring of fungal symbionts. GAH led the writing; all authors discussed results and commented on the article. GAH agrees to serve as the author responsible for contact and ensuring communication.

Funding This work is financially supported by the NERC to KJF, SP (NE/N00941X/1; NE/S009663/1) and MIB (NE/N009665/1). KJF is supported by a BBSRC Translational Fellowship (BB/M026825/1) and a Philip Leverhulme Prize (PLP-2017-079).

Data availability Data are available from the corresponding author.

\section{Declarations}

Consent to participate All author's consent to participate.

Consent for publication All author's consent to publication.

Conflict of interest The authors declare no competing interests.
Open Access This article is licensed under a Creative Commons Attribution 4.0 International License, which permits use, sharing, adaptation, distribution and reproduction in any medium or format, as long as you give appropriate credit to the original author(s) and the source, provide a link to the Creative Commons licence, and indicate if changes were made. The images or other third party material in this article are included in the article's Creative Commons licence, unless indicated otherwise in a credit line to the material. If material is not included in the article's Creative Commons licence and your intended use is not permitted by statutory regulation or exceeds the permitted use, you will need to obtain permission directly from the copyright holder. To view a copy of this licence, visit http://creativecommons.org/licenses/by/4.0/.

\section{References}

Alberton O, Kuyper TW, Gorissen A (2005) Taking mycocentrism seriously: mycorrhizal fungal and plant responses to elevated $\mathrm{CO}_{2}$. New Phytol 167:859-868

Albornoz FE, Hayes PE, Orchard S, Clode PE, Nazeri NK, Standish RJ et al (2020) First cryo-scanning electron images and x-ray microanalyses of Mucoromycotinana fine root endophytes in vascular plants. Front Microbiol 11:208

Ames RN, Reid CPP, Poter LK, Cambardella C (1983) Hyphal uptake and transport of nitrogen from two $15 \mathrm{~N}$-labelled sources by Glomus mosseae, a vesicular-arbuscular mycorrhizal fungus. New Phytol 95:381-396

Averill C, Turner BL, Finzi AC (2014) Mycorrhiza-mediated competition between plants and decomposers drives soil carbon storage. Nature 505:543-545

Berbee ML, James TY, Strullu-Derrien C (2017) Early diverging fungi: diversity and impact at the dawn of terrestrial life. Annu Rev Microbiol 71:41-60

Berner RA (2006) Geocarbsulf: A combined model for Phanerozoic atmospheric $\mathrm{O}_{2}$ and $\mathrm{CO}_{2}$. Geochim Cosmochim Acta 70:5653-5664

Bergman NM, Lenton TM, Watson AJ (2004) COPSE: a new model of biogeochemical cycling over Phanerozoic time. Am J Sci 304:397-437

Bidartondo MI, Read DJ, Trappe JM, Merckx V, Ligrone R, Duckett JG (2011) The dawn of symbiosis between plants and fungi. Biol Lett 7:574-577

Blair JE. (2009). The fungi in the timetree of life. Hedges SB \& Kumar S. eds.

Brundrett M, Bougher N, Dell B, Grove T, Malajczuk N (1996) Working with mycorrhizas in forestry and agriculture. Pirie Printers, Canberra, Monograph, Australian Centre for International Agricultural Research

Cameron DD, Leake JR, Read DJ (2006) Mutualistic mycorrhiza in orchids: evidence from plant-fungus carbon and nitrogen transfers in the green-leaved terrestrial orchid Goodyera repens. New Phytol 171:405-416

Cameron DD, Johnson I, Leake JR, Read DJ (2007) Mycorrhizal acquisition of inorganic phosphorus by the green-leaved terrestrial orchid Goodyera repens. Ann Bot 99:831-834

Cotton TA (2018) Arbuscular mycorrhizal fungal communities and global change. An uncertain future FEMS Microbiol Ecol 94:179

Desirò A, Duckett JG, Pressel S, Villarreal JC, Bidartondo MI (2014) Fungal symbioses in hornworts: a chequered history. Proc R Soc B: Biol Sci 280:20130207

Duckett JG, Carafa A, Ligrone R (2006) A highly differentiated glomeromycotean association with the mucilage-secreting, primitive antipodean liverwort Treubia (Treubiaceae): Clues to the origins of mycorrhizas. Am J Bot 93:797-813 
Field KJ, Cameron DD, Leake JR, Tille S, Bidartondo MI, Beerling DJ (2012) Contrasting arbuscular mycorrhizal responses of vascular and non-vascular plants to a simulated Palaeozoic $\mathrm{CO}_{2}$ decline. Nat Comms 3:1-8

Field KJ, Rimington WR, Bidartondo MI, Allinson KE, Beerling DJ, Cameron DD et al (2015a) First evidence of mutualism between ancient plant lineages (Haplomitropsida liverworts) and Mucoromycotina fungi and its response to simulated Palaeozoic changes in atmospheric $\mathrm{CO}_{2}$. New Phytol 205:743-756

Field KJ, Duckett PS, JG, Rimington WR, Bidartondo MI. (2015b) Symbiotic options for the conquest of land. Trends Ecol Evol 30:477-486

Field KJ, Rimington WR, Bidartondo MI, Allinson KE, Beerling DJ, Cameron DD et al (2016) Functional analysis of liverworts in dual symbiosis with Glomeromycota and Mucoromycotina fungi under simulated Palaeozoic $\mathrm{CO}_{2}$ decline. ISME J 10:1514-1526

Field KJ, Pressel S (2018) Unity in diversity: structural and functional insights into the ancient partnerships between plants and fungi. New Phytol 220:996-1011

Field KJ, Bidartondo MI, Rimington WR, Hoysted GA, Beerling D, Cameron DD et al (2019) Functional complementarity of ancient plant-fungal mutualisms: contrasting nitrogen, phosphorus and carbon exchanges between Mucoromycotina and Glomeromycotina fungal symbionts of liverworts. New Phytol 223:908-921

Field KJ, Daniell T, Johnson D, Helgason T (2020) Mycorrhizas for a changing world: sustainability, conservation, and society. Plants, People, Planet 2:98-103

Fransson FMA, Taylor AFS, Finlay RD (2005) Mycelial production, spread and root colonisation by ectomycorrhizal fungi Hebeloma crustuliniforme and Paxillus involutus under elevated atmospheric $\mathrm{CO}_{2}$. Mycorrhiza 15:25-31

Fransson FMA, Anderson IC, Alexander IJ (2007) Ectomycorrhizal fungi in culture respond differently to increased carbon availability. FEMS Microbiol Ecol 61:246-257

Galloway AF, Pederson MJ, Merry B, Marcus SE, Blacker J, Benning LG et al (2018) Xyloglucan is released by plants and promotes soil particle aggregation. New Phytol 217:1128-1136

Hodge A, Campbell CD, Fitter AH (2001) An arbuscular mycorrhizal fungus accelerates decomposition and acquires nitrogen directly from organic material. Nature 413:297-299

Hoysted GA, Kowal J, Jacob A, Rimington WR, Duckett JG, Pressel $S$ et al (2018) A mycorrhizal revolution. Curr Opin Plant Biol 44:1-6

Hoysted GA, Jacob A, Kowal J, Giesemann P, Bidartondo MI, Duckett JG et al (2019) Mucoromycotina fine root endophyte fungi form nutritional mutualisms with vascular plants. Plant Physiol 181:565-577

Kenrick P, Crane PR (1997) Origin and early diversification of land plants. Smithsonian Institution Press

Kiers ET, Duhamel M, Beesetty Y, Mensah JA, Franken O, Verbruggen E et al (2011) Reciprocal rewards stabilise cooperation in the mycorrhizal symbiosis. Science 333:880-882

Kowal J, Arrigoni E, Serra J, Bidartondo M. (2020). Prevalence and phenology of fine root endophyte colonization across populations of Lycopodiella inundata. Mycorrhiza: 30(5): 577-587

Krings M, Taylor TN, Dotzler N. (2012). Fungal endophytes as a driving force in land plant evolution: evidence from the fossil record. Biocomplexity Plant-Fungal Interactions: 5-28

Leake J, Johnson D, Donnelly D, Muckle G, Boddy L, Read D (2004) Networks of power and influence: the role of mycorrhizal mycelium in controlling plant communities and agroecosystem functioning. Can J Bot 82:1016-1045

Leaky AD, Lau JA (2012) Evolutionary context for understanding and manipulating plant responses to past, present and future atmospheric $\left[\mathrm{CO}_{2}\right]$. Phil Trans R Soc B: Biol Sci 367:613-629
Lenton TM, Dahl TW, Daines SJ, Mills BJW, Ozaki K, Saltzman MR et al (2016) Earliest land plants created modern levels of atmospheric oxygen. Proc Nat Acad Sci USA 113:9704-9709

Meinshausen M, Smith SJ, Calvin K, Daniel JS, Kainuma MLT, Lamarque JF et al (2011) The RCP greenhouse gas concentrations and their extensions from 1765 to 2300. Clim Change 109:213

Morris JL, Puttick MN, Clark JW, Edwards D, Kenrick P, Pressel S et al (2018) The timescale of early land plant evolution. Proc Nat Acad Sci USA 115:2274-2283

Nicolson TH. (1967). Vesicular-arbuscular mycorrhiza - a universal plant symbiosis. Sci Prog (1933): 561-581

Orchard S, Hilton S, Bending GD, Dickie IA, Standish RJ, Gleeson DB et al (2017a) Fine endophytes (Glomus tenue) are related to Mucoromycotina, not Glomeromycota. New Phytol 213:481-486

Orchard S, Standish RJ, Dickie IA, Renton M, Walker C, Moot D et al (2017b) Fine root endophytes under scrutiny: a review of the literature on arbuscular-producing fungi recently suggested to belong to the Mucoromycotina. Mycorrhiza 27:619-638

Orchard S, Standish RJ, Nicol D, Dickie IA, Ryan MH (2017c) Sample storage conditions alter colonisation structures of arbuscular mycorrhizal fungi and particularly fine root endophyte. Plant Soil 412:35-42

Pirosynski KA, Malloch DW (1975) The origin of land plants: a matter of mycoheterotrophy. Biosyst 6:153-164

Radhakrishnan GV, Keller J, Rich MK, Vernié T, Mbadinga DLM, Vigneron $\mathrm{N}$ et al (2020) An Ancestral signalling pathway is conserved in intracellular symbioses-forming plant lineages. Nat Plants 6:280-289

Rasmussen KK, Lawesson JE (2002) Lycopodiella inundata in British plant communities and reasons for its decline. Watsonia 24:45-56

Read DJ (1991) Mycorrhizas in ecosystems. Experientia 47:376-391

Redecker D (2000) Specific PCR primers to identify arbuscular mycorrhizal fungi with colonised roots. Mycorrhiza 10:73-80

Rillig MC (2004) Arbuscular mycorrhizae and terrestrial ecosystem processes. Ecol Lett 7:740-754

Rimington WR, Pressel S, Duckett JG, Bidartondo MI (2015) Fungal associations of basal vascular plants: reopening a closed book? New Phytol 205:1394

Rimington WR, Duckett JG, Field KJ, Bidartondo M, Pressel S. (2020). The distribution and evolution of fungal symbioses in ancient lineages of land plants. Mycorrhiza 1-27

Smith SE, Smith FA (2011) Roles of arbuscular mycorrhizas in plant nutrition and growth: new paradigms from cellular to ecosystem scales. Annu Rev Plant Biol 62:227-250

Spatafora JW, Aime MC, Grigoriev IV, Martin F, Stajich JE, Blackwell M (2017) The fungal tree of life: from molecular systematics to genome-scale phylogenies. Microbiol Spec 5:1-32

Strullu-Derrien C, Strullu DG (2007) Mycorrhization of fossil and living plants. CR Palevol 6-7:483-494

Strullu-Derrien C, Kenrick P, Pressel S, Duckett JG, Rioult JP, Strullu DG (2014) Fungal associaions in Horneophyton ligneri from the Rynie Chert (c. 407 million years old) closely resemble those in extant lower land plants: novel insights into ancestral plant-fungus symbioses. New Phytol 203:964-979

Thirkell TJ, Pastok D, Field KJ (2019) Carbon for nutrient exchange between arbuscular mycorrhizal fungi and wheat varies according to cultivar and changes in atmospheric carbon dioxide concentration. Global Change Biol 26:1725-1738

Wijayawardene NN, Pawłowska J, Letcher PM, Kirk PM, Humber RA, Schüßler A et al (2018) Notes for genera: basal clades of Fungi (including Aphelidiomycota, Basidiobolomycota, Blastocladiomycota, Calcarisporiellomycota, Caulochytriomycota, Chytridiomycota, Entomophthoromycota, Glomeromycota, Kickxellomycota, Monoblepharomycota, Mortierellomycota, Mucoromycota, Neocallimastigomycota, Olpidiomycota, Rozellomycota and Zoopagomycota). Fungal Diversity 92:43-129 
Wilson JP, Montanez IP, White JD, DiMichele WA, McElwain JC, Poulson CJ et al (2017) Dynamic Carboniferous tropical forets: new views of plant function and potential for physiological forcing of climate. New Phytol 215:1333-1353

Wipf D, Krajinski F, van Tuinen D, Recorbet G, Courty PE (2019) Trading on the arbuscular mycorrhiza market: from arbuscules to common mycorrhizal networks. New Phytol 223:1127-1142
Zheng C, Ji B, Zhang J, Zhang F, Bever JD (2015) Shading decreases plant carbon preferential allocation towards the most beneficial mycorrhizal mutualist. New Phytol 205:361-368

Publisher's Note Springer Nature remains neutral with regard to jurisdictional claims in published maps and institutional affiliations. 